\title{
Paradoxical cerebral embolism during endoscopic esophageal stenting in a patient with esophageal
}

\section{cancer}

A 77-year-old man with a recurrent esophageal cancer presented with progressive dysphagia. Computed tomography of the chest, esophagogastroscopy, and pharyngesophagography showed an approximately $8.3-\mathrm{cm}$ long malignant stricture in the mid-esophagus ( $\bullet$ Fig. 1 ). A 10-cm long, esophageal self-expanding metallic stent (SEMS) was deployed under conscious sedation ( $\bullet$ Fig. 2 ). The patient's level of consciousness deteriorated immediately following the procedure, with left hemiparesis, decreased mentation, and dysarthria. Magnetic resonance imaging of the brain revealed acute cortical infarction ( $\bullet$ Fig.3). Transcranial Doppler ultrasound with an agitated saline test demonstrated a patent foramen ovale (PFO). It was concluded that during the procedure the patient had a paradoxical tumor embolism via the PFO, causing multifocal cerebral infarction [1]. The patient was discharged with no improvement in his symptoms.

Several cases of air embolism during endoscopy have been published [2-4]. However, tumor embolization to the brain causing cerebral infarction during esophageal stenting has not been reported. In the present case, we suggest that the deployment of the SEMS at the malignant obstruction resulted in injury to the small vessels in the esophagus, allowing tumor cells to enter the venous circulation in response to the positive pressure inside the stent lumen, produced by self-expansion [3]. After entering the venous system, the tumor emboli traveled to the right side of the heart, passed through the PFO into the left atrium and then into the left ventricle, thus entering the systemic circulation and finally causing multiple cerebral infarctions $[1,2,5]$.

Although tumor embolization to the brain during endoscopy is a rare cause of stroke in cancer patients, it causes serious neurological deficits. It is necessary to distinguish this complication from air embolism during endoscopy, as the treatment is different, although both have similar mechanisms. Early detection of neurological symptoms and a correct diagnosis may improve the outcome in these patients.

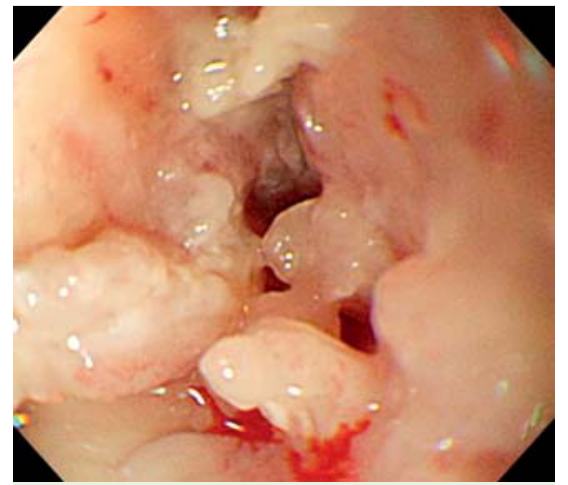

Fig. 1 Esophagogastroscopy in a 77-year-old man with a recurrent esophageal cancer and progressive dysphagia showing circumferential luminal narrowing due to an obstructive esophageal mass with easy-touch bleeding, located $35 \mathrm{~cm}$ from the incisors.
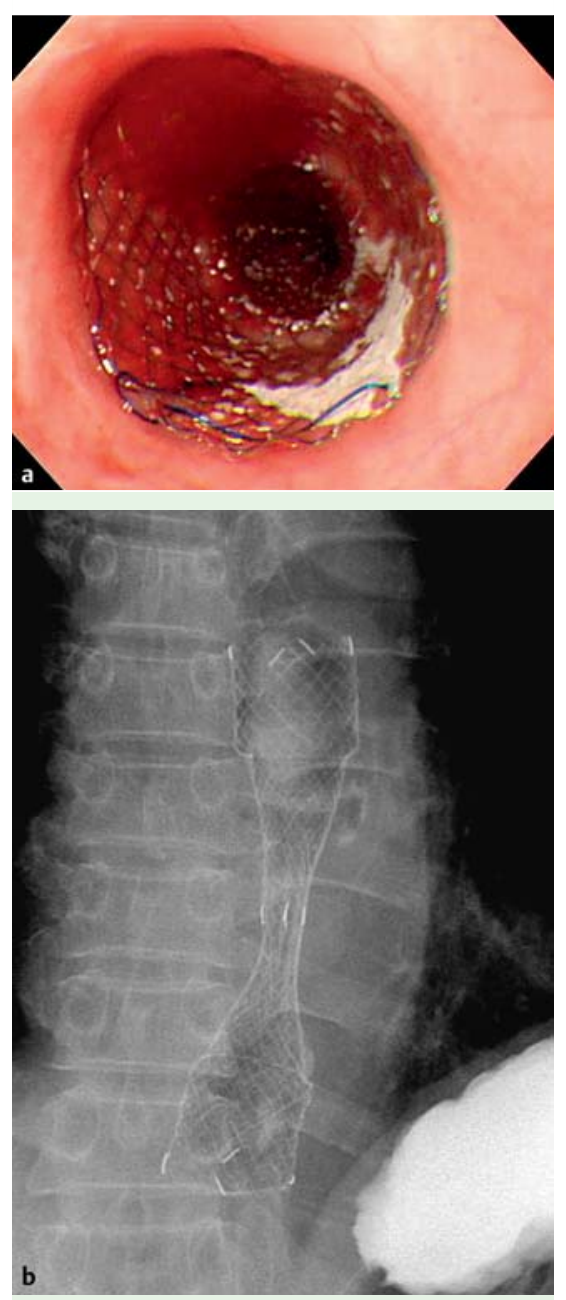

Fig. 2 a, b A 10-cm long self-expanding covered esophageal stent was used.
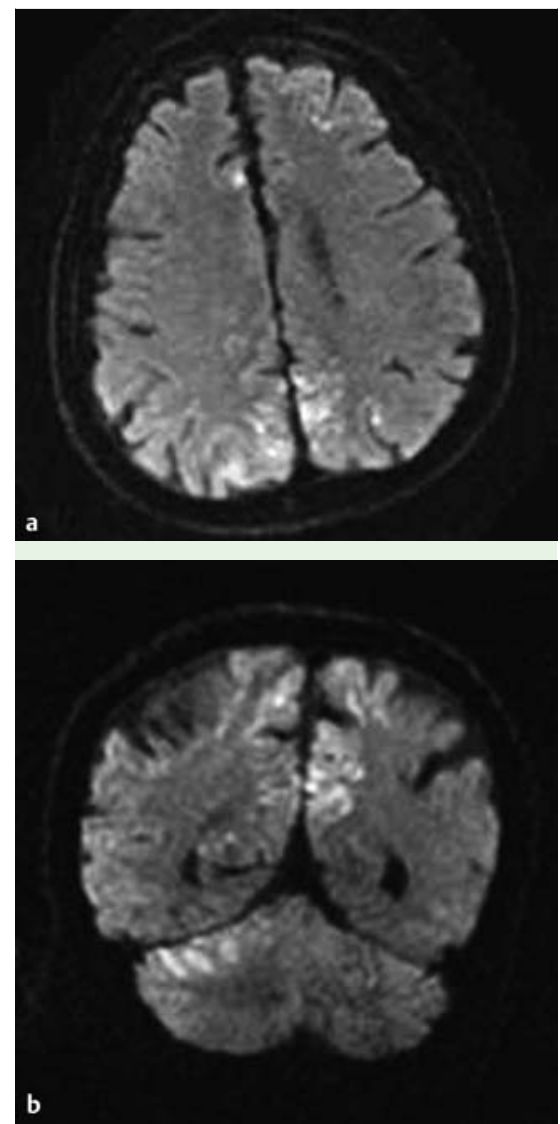

Fig. 3 a, b Magnetic resonance imaging (MRI) of the head showing multifocal lesions with restricted diffusion in both cerebral hemispheres and the right cerebellum, suggesting acute cortical infarction. 
Endoscopy_UCTN_Code_CPL_1AH_2AD

Competing interests: None

H. N. Kim¹, D. E. Kim¹, J. E. Hwang1, W. K. Bae', S. H. Cho' ${ }^{1}$, Y. E. Joo ${ }^{2}$, K. H. Choi ${ }^{3}$, I. J. Chung ${ }^{1}$, H. J. Shim ${ }^{1}$

${ }^{1}$ Division of Hematology-Oncology, Department of Internal Medicine, Chonnam National University Medical School, Gwangju, Korea

2 Division of Gastroenterology, Department of Internal Medicine, Chonnam National University Medical School, Gwangju, Korea

${ }^{3}$ Department of Neurology, Chonnam National University Medical School, Gwangju, Korea

\section{References}

1 Iguchi $Y$, Kimura K, Kobayashi $K$ et al. Ischaemic stroke with malignancy may often be caused by paradoxical embolism. J Neurol Neurosurg Psychiatry 2006; 77: 1336-1339

2 Finsterer J, Stollberger C, Bastovansky A. Cardiac and cerebral air embolism from endoscopic retrograde cholangio-pancreatography. Eur J Gastroenterol Hepatol 2010; 22: 1157-1162

3 Green BT, Tendler DA. Cerebral air embolism during upper endoscopy: case report and review. Gastrointest Endosc 2005; 61: 620-623

4 Lopez JC, Perez X, Esteve F. Cerebral air embolism during upper endoscopy. Endoscopy 2010; 42: E41

5 McGaw D, Harper R. Patent foramen ovale and cryptogenic cerebral infarction. Intern Med J 2001; 31: $42-47$

\section{Bibliography}

DOI http://dx.doi.org/ 10.1055/s-0032-1310143 Endoscopy 2012; 44: E406-E407

(c) Georg Thieme Verlag KG

Stuttgart · New York

ISSN 0013-726X

\section{Corresponding author}

\section{H. J. Shim}

Division of Hematology-Oncology Department of Internal Medicine

Chonnam National University Hwasun Hospital 160 Ilsim-ri

Hwasun-eup

Hwasun-gun 519-809

Korea

Fax: +82-61-379-8009

hjnhj@chonnam.ac.kr 